\title{
Effects of physicochemical parameters on volatile sulphur compound formation from L-methionine catabolism by non-growing cells of Kluyveromyces lactis
}

\author{
Yuyun Lu', Margarete Nawrath ${ }^{1}$, Jingcan Sun ${ }^{1}$ and Shao-Quan Liu ${ }^{1,2^{*}}$
}

\begin{abstract}
The present study investigated for the first time the effects of various physicochemical parameters on the production of volatile sulphur compounds (VSCs) by non-growing cells of Kluyveromyces lactis supplemented with L-methionine. The results showed that the production of VSCs positively correlated with the cell biomass, but it seemed that no clear relationship with $\mathrm{L}$-methionine concentration existed. Temperature and $\mathrm{pH}$ significantly affected the formation of VSCs with more production at $30^{\circ} \mathrm{C}$ and $\mathrm{pH} 5$, respectively. Nitrogen supplementation (in the form of diammonium phosphate, DAP) repressed the production of VSCs. It is interesting to note that DAP and yeast extract supplementation induced the production of methional, but not $\mathrm{Mn}^{2+}$ supplementation. The presence of $\mathrm{Mn}^{2+}$ improved the production of methionol and dimethyl disulphide, but inhibited the formation of S-methyl thioacetate. The study indicated that optimization of physicochemical conditions and media composition would be crucial for producing L-methionine-derived VSC bioflavor.
\end{abstract}

Keywords: Kluyveromyces lactis, L-Methionine, Volatile sulphur compounds, Bio-flavors

\section{Introduction}

Volatile sulphur compounds (VSCs) are responsible for the intensive odor of vegetables such as cabbage, onions and garlic. They normally have distinctive desirable or undesirable odor qualities and are frequently found in fermented products like wine, cheese or beer where they significantly impact sensorial attributes due to their extremely low odor detection thresholds ranging from $\mathrm{ng} / \mathrm{L}$ to $\mu \mathrm{g} / \mathrm{L}$ (Mestres et al. 2000; Ugliano and Henschke 2009; McGorrin 2011).

The sulfur-containing amino acids such as L-cysteine and L-methionine are the main precursors of VSCs in fermented products. Methanethiol is the first intermediate from L-methionine metabolism by yeasts and is

\footnotetext{
${ }^{*}$ Correspondence: chmlsq@nus.edu.sg

1 Food Science and Technology Program, Department of Chemistry, National University of Singapore, Science Drive 3, Singapore 117543, Singapore

Full list of author information is available at the end of the article
}

also regarded as a precursor of many other VSCs (Hanniffy et al. 2009). Methanethiol was found in various foods including blue cheese and alcoholic beverages with contribution of a putrid or cooked cabbage-like flavor (Gonda et al. 2013; Ochiai et al. 2012; Hazelwood et al. 2008; Landaud et al. 2008). Due to its high oxidation sensitivity, methanethiol is usually rapidly converted into dimethyl disulfide (DMDS) and dimethyl trisulfide (DMTS) (Chin and Lindsay 1994). Further, DMDS and DMTS could be transformed back into methanethiol during fermentation. DMDS could contribute to a garlicky and onion-like odor, which is of benefit to the flavor of some fermented foods such as Tuber melanosporum (Xiao et al. 2015) and cheese (Fuchsmann et al. 2015).

Methional is also considered as a catabolite from L-methionine metabolism by cheese-ripening bacteria or yeasts with a characteristic odor of boiled potatoes. In addition, methional is known for its light-induced off-flavor in milk and is first formed via Strecker degradation, 
due to it being unstable, it could decompose to mercaptomethane, and finally to DMDS (Ahn et al. 2016). Seow et al. (2010) reported that methional could also be produced from $\mathrm{L}$-methionine metabolism by yeasts in coconut cream.

$S$-Methyl thioesters can be formed via enzymatically from L-methionine metabolism by cheese-ripening yeasts (Martínez-Cuesta et al. 2013). The formation of $S$-methyl thioesters is relatively dependent on $\mathrm{pH}$ and temperature in the presence of methanethiol and short-chain fatty acids which need to be activated by CoA-SH (Helinck et al. 2000; Martínez-Cuesta et al. 2013). S-Methyl thioacetate (MTA), which has a boiled cauliflower-like aroma, is the most prevalent thioester found in cheeses. MTA was most frequently associated with cabbage and cheesy odors, but it is an unsuspected odor compound in fresh strawberries (Schulbach et al. 2004).

Various microorganisms have been reported to possess the VSC production capacity including bacteria (e.g. Brevibacterium linens or Lactococcus lactis) and yeasts (e.g. Geotrichum candidum, Yarrowia lipolytica and Kluyveromyces lactis) in cheese and wine production (Arfi et al. 2002, 2003; Spinnler et al. 2001; CernatBondar et al. 2005; Kagkli et al. 2006a, b). Most of VSCs are detected as key aroma compounds and contribute to the overall flavor of cheeses. However, they could also contribute to off-flavors when the concentration is in excess, especially in wine or beer (Landaud et al. 2008).

Previous studies showed that yeasts are able to metabolize L-methionine into VSCs via the Ehrlich pathway (McGorrin 2011; Seow et al. 2010; Tan et al. 2012). K. lactis has received increasing attention in industrial biotechnology over the last decade due to its distinctive fermentative capabilities. This yeast plays an important role in formation of VSCs and is mainly involved in cheese aromatization during the ripening process. Furthermore, $K$. lactis is unable to grow under anaerobic conditions and an oxygen limitation will cause a significant decrease of its growth rate (Merico et al. 2009). In contrast to other yeasts, $K$. lactis has the ability to utilize lactose due to the capacity of producing $\beta$-galactosidase (Rodicio and Heinisch 2013). In addition, $K$. lactis has been identified as a cheese ripening yeast that has a great ability in VSC biogenesis owing to its genetic makeup (Cholet et al. 2007).

Recently, non-growing cells as a whole-cell biocatalysis system have been used to improve the biotechnological process (Julsing et al. 2012). Non-growing cells are metabolically active microorganisms which are applied to a synthetic medium supplemented with a product precursor. This procedure is based on energy limitation to inhibit biomass production and increase product yield by enhancing the efficiency of metabolization (Julsing et al. 2012). Using non-growing cells of $K$. lactis, VSC biosynthesis can be more efficient and may be more economically viable. The control of metabolic processes of L-methionine provides biotechnological ways to produce bioflavor product and at the same time, addressing consumer preferences for natural ingredients (Rodicio and Heinisch 2013). In this study, the whole-cell-based catabolism of L-methionine was conducted with the objectives of understanding L-methionine metabolism and VSC formation by $K$. lactis under various physicochemical conditions. The formation of VSCs was examined in a model system consisting of non-growing cells of $K$. lactis and L-methionine.

\section{Materials and methods \\ Reagents and standards}

Malt extract, yeast extract, bacteriological peptone and potato dextrose agar (PDA) were purchased from Oxoid (Hamphire, England). Manganese (II) chloride tetrahydrate $\left(\mathrm{MnCl}_{2} \cdot 4 \mathrm{H}_{2} \mathrm{O}\right)$ and $\mathrm{HCl}$ were purchased from Merck KGaA (Darmstadt, Germany). Sucrose was purchased from Reckitt Benckiser (Glucolin ${ }^{\circledR}$, Petaling Jaya, Malaysia). Sodium phosphate monobasic dihydrate $\left(\mathrm{NaH}_{2} \mathrm{PO}_{4} \cdot 2 \mathrm{H}_{2} \mathrm{O}\right)$, sodium phosphate dibasic anhydrous $\left(\mathrm{Na}_{2} \mathrm{HPO}_{4}\right)$, L-methionine $(\geq 99 \%$, non-animal source) and diammonium phosphate (DAP, purity $\geq 98 \%$ ) were purchased from Sigma-Aldrich (Unterhaching, Germany).

\section{Culture preparation and cell harvesting}

Kluyveromyces lactis KL71 was obtained from Danisco Singapore Pte Ltd (Singapore). The freeze-dried yeast was (with shaking, $80 \mathrm{rpm}$ ) cultured at $25^{\circ} \mathrm{C}$ for $24 \mathrm{~h}$ in sterile broth $(\mathrm{pH} 5.0,1 \mathrm{M} \mathrm{HCl})$ containing $2 \%(\mathrm{w} / \mathrm{v})$ glucose, $0.25 \%(\mathrm{w} / \mathrm{v})$ yeast extract, $0.25 \%(\mathrm{w} / \mathrm{v})$ malt extract and $0.25 \%(\mathrm{w} / \mathrm{v})$ bacteriological peptone. After that, the pure culture was aliquoted into $1-\mathrm{mL}$ sterile tubes and stored at $-80{ }^{\circ} \mathrm{C}$. The pre-culture of $K$. lactis KL71 was prepared by inoculating $5 \%(\mathrm{v} / \mathrm{v})$ of a pure culture in the sterilized broth $(100 \mathrm{~mL})$ and incubated at $30{ }^{\circ} \mathrm{C}$ for $24 \mathrm{~h}$ under sterile conditions with shaking continuously at $80 \mathrm{rpm}$ in water bath. The obtained pre-culture was further inoculated into the sterile broth $(3 \%, 3 \mathrm{~L})$. The sterile broth was the same as above except the amount of glucose was increased to $3 \%(\mathrm{w} / \mathrm{v})$.

The propagated yeast cells were centrifuged in sterile 50-mL PP tubes (Greiner Bio-one, Germany) at $4700 \mathrm{rpm}$ for 15 min (Centrifuge 5810R, Eppendorf AG, Hamburg, Germany). The supernatant was discarded and the obtained yeast cells were washed twice with a sterile sodium phosphate buffer ( $\mathrm{pH} 5,100 \mathrm{mM}$ ), and then centrifuged at $8000 \mathrm{rpm}$ for $10 \mathrm{~min}$ at $4{ }^{\circ} \mathrm{C}$. The supernatant was decanted and the washed cells were re-suspended 
in $100 \mathrm{~mL}$ of the phosphate buffer (pH 5, $100 \mathrm{mM})$ and stored overnight $(<24 \mathrm{~h})$ at $4{ }^{\circ} \mathrm{C}$.

\section{Whole-cell biocatalysis conditions and procedures}

A total of eight parameters were investigated at three levels. For investigations on physicochemical parameters (biomass, L-methionine concentration, agitation rate/ aeration, temperature and $\mathrm{pH}$ ), the factor level which exhibited the highest methionol production was selected for subsequent treatments. For parameters of the supplementation with nitrogen (DAP), yeast extract and $\mathrm{Mn}^{2+}$, they were investigated individually by using the selected physicochemical parameters in triplicate.

Non-growth media consisted of yeast cells and L-methionine as shown in Table 1 and were filled up with sterile $100 \mathrm{mM}$ phosphate buffer to a total volume of $100 \mathrm{~mL}$. Whole-cell biocatalysis was conducted in sterilized 250-mL Schott glass bottles with screw caps (Schott AG, Delligsen, Germany).

To investigate the biomass, the optical density (OD) was measured with a UV-Vis spectrophotometer (UVmini-1240, Shimadzu, Kyoto, Japan) at $600 \mathrm{~nm}$. The reaction mixtures comprised of $0.5 \%$ L-methionine in $100 \mathrm{mM}$ phosphate buffer at $\mathrm{pH} 5$ and different amounts of $K$. lactis 71 with $\mathrm{OD}_{600}$ of 2, 4 and 6 were incubated aerobic for $48 \mathrm{~h}$ in water bath at $30^{\circ} \mathrm{C}$ with $80 \mathrm{rpm}$.

An L-methionine stock solution (4\%,w/v) was prepared in $100 \mathrm{mM}$ sodium phosphate buffer and was filtered by using sterile Acrodisc $^{\circledR}$ syringe filters with a Supor ${ }^{\circledR}$ membrane $(0.20-\mu \mathrm{m}$, Pall Corp., Port Washington, USA) before adding aseptically to the non-growth media to achieve the final cell biomass (Table 1).

Agitation and temperature were controlled by using shaking water bath (SW22, Julabo GmbH, Seelbach, Germany). Without agitation, Schott bottles with media were screwed tightly to create a near anaerobic condition. At 80 and $120 \mathrm{rpm}$, the caps were screwed loosely to ensure

\section{Table 1 Factor levels investigated for each parameter}

\begin{tabular}{|c|c|c|c|c|}
\hline \multirow[t]{2}{*}{ Run } & \multirow[t]{2}{*}{ Parameter } & \multicolumn{3}{|c|}{ Factor levels } \\
\hline & & Low & Medium & High \\
\hline 1 & Biomass $\left(\mathrm{OD}_{600}\right.$ value $)$ & 2 & 4 & 6 \\
\hline 2 & L-Methionine concentration (w/v) & $0.1 \%$ & $0.5 \%$ & $1.0 \%$ \\
\hline 3 & Agitation rate (rpm) & 0 & 80 & 120 \\
\hline 4 & Temperature $\left({ }^{\circ} \mathrm{C}\right)$ & 25 & 30 & 38 \\
\hline 5 & pH (100 mM phosphate buffer) & 4 & 5 & 6 \\
\hline 6 & Nitrogen supplementation (w/v) & $0 \%$ & $0.1 \%$ & $0.3 \%$ \\
\hline 7 & Yeast extract $(\mathrm{w} / \mathrm{v})$ & $0 \%$ & $0.1 \%$ & $0.3 \%$ \\
\hline 8 & $\mathrm{Mn}^{2+}$ supplementation $(\mathrm{mM})$ & 0 & 1 & 10 \\
\hline
\end{tabular}

\#6: nitrogen = diammonium phosphate aeration. The $\mathrm{pH}$ of media was adjusted by varying the amounts of $\mathrm{NaH}_{2} \mathrm{PO}_{4}$ and $\mathrm{Na}_{2} \mathrm{HPO}_{4}$. Additionally, a $\mathrm{pH}$ meter (Metrohm Ltd., Herisau, Switzerland) was used for verification.

For supplemented treatments, the preparation was carried out as described above. Diammonium phosphate was used as the nitrogen source. Yeast extract was identical to the one used in broth. Both stock solutions were filter sterilized. Manganese (II) chloride tetrahydrate as the $\mathrm{Mn}^{2+}$ source was diluted in $100 \mathrm{mM}$ phosphate buffer and sterilized in an autoclave (Hirayama HVE-50 Hiclave, Tokyo, Japan) at $121^{\circ} \mathrm{C}$ for $20 \mathrm{~min}$.

Samples $(6 \mathrm{~mL})$ were taken at $0,2,8,24$ and $48 \mathrm{~h}$. The whole-cell biocatalysis was stopped by removing yeast cells via centrifugation $(8000 \mathrm{rpm})$ at $4{ }^{\circ} \mathrm{C}$ for $10 \mathrm{~min}$, and the $\mathrm{pH}$ of the supernatant was adjusted to 2.5 by adding $1.0 \mathrm{M} \mathrm{HCl}$ before volatile analysis. All samples were stored at $-80^{\circ} \mathrm{C}$ before analysis.

\section{Yeast cell quantification}

The viable cells in initial non-growth media $(0 \mathrm{~h})$ and at the end of incubation $(48 \mathrm{~h})$ were obtained by spread plating on potato dextrose agar (PDA). Plates were incubated at $25{ }^{\circ} \mathrm{C}$ for $48 \mathrm{~h}$ (Sanyo Incubator, Illinois, USA). In addition, streaking was carried out to confirm the absence of contaminants of both the pre-culture and reaction media before and after incubation $(0$ and $48 \mathrm{~h})$.

\section{Volatile sulfur compound analysis}

All samples were analyzed to identify and semi-quantify volatile compounds using head space solid-phase micro extraction coupled with gas chromatography-mass spectrometry and flame ionization detection (HS-SPMEGC-MS-FID) as reported previously (Tan et al. 2012; Seow et al. 2010). The volatile sulfur compounds were identified by comparing the mass spectra with NIST 8.0 and Wiley 275 MS library.

\section{Statistical analysis}

The mean values and standard deviations were calculated based on the data obtained from triplicate incubations. All data were subjected to one-way analysis of variance (ANOVA) to investigate the significant difference among factor levels and to determine optimal conditions for methionol and other VSC production. All tests of significance were conducted at a probability level of $P$ value less than 0.05 .

\section{Results}

Effect of physicochemical parameters on VSC production by non-growing cells of $K$. lactis

The control which contained yeast cells only in buffer showed no VSC production after $48 \mathrm{~h}$ ' incubation. The 
effects of different physicochemical parameters on kinetic changes of VSC production including methionol, MTA and DMDS are shown in Figs. 1, 2, 3, 4, 5. Other VSCs were not detected.

The effect of biomass on the production and kinetic changes of methionol, MTA and DMDS is shown in Fig. 1 . The production of VSCs positively correlated with the biomass as measured as $\mathrm{OD}_{600}$. Methionol increased sharply and reached its maximum at 2 or $8 \mathrm{~h}$ and then decreased slightly or kept stable (Fig. 1). The production of methionol between 8 and $48 \mathrm{~h}$ was significantly higher at $\mathrm{OD}_{600} 6$ than that at $\mathrm{OD}_{600} 4$ and $\mathrm{OD}_{600} 2$ (Fig. 1 and Additional file 1: Table S1). MTA increased gradually by $24 \mathrm{~h}$ and then declined slightly or remained stable (Fig. 1). Production of MTA at $\mathrm{OD}_{600} 4$ and 6 was significantly higher than that at OD2, whereas no significant difference was found between $\mathrm{OD}_{600} 4$ and $\mathrm{OD}_{600} 6$ (Fig. 1 and Additional file 1: Table S1). DMDS increased gradually and kept stable except at $\mathrm{OD}_{600} 6$, which increased continuously (Fig. 1). It is important to note that the higher the $\mathrm{OD}_{600}$ value, the significantly higher amount of DMDS was produced (Fig. 1 and Additional file 1: Table S1). Therefore, $\mathrm{OD}_{600} 6$ was selected and used in subsequent treatments.
The effect of L-methionine concentration (0.1, 0.5 and $1.0 \%)$ on the production and kinetic changes of VSCs is shown in Fig. 2. All treatments followed similar kinetic changes with methionol increasing to its maximum at $8 \mathrm{~h}$ $(0.1$ and $1.0 \%)$ or $24 \mathrm{~h}(0.5 \%)$ and then declined onwards (Fig. 2). Similarly, the production of MTA increased gradually by $24 \mathrm{~h}$ and then declined in all treatments (Fig. 2). As for DMDS, it increased gradually but with relatively higher DMDS production at L-methionine concentration of 0.1 and $0.5 \%$ (Fig. 2). The production of DMDS may partially come from the oxidation of methanethiol released from the hydrolysis of MTA. It seemed that there was no significant effect of L-methionine concentration on VSC production among all treatments, except DMDS between 0.1 and $1.0 \%$ of L-methionine (Additional file 1: Table S1). Taking analytical variations into consideration, $1.0 \% \mathrm{~L}$-methionine was selected and used in subsequent treatments.

The effect of aeration on the production and kinetic changes of VSCs is shown in Fig. 3 and the aeration seemed to decrease the formation of methionol. The production of methionol increased gradually by $24 \mathrm{~h}$ and then remained largely stable under static condition. The amount of methionol produced was significantly higher
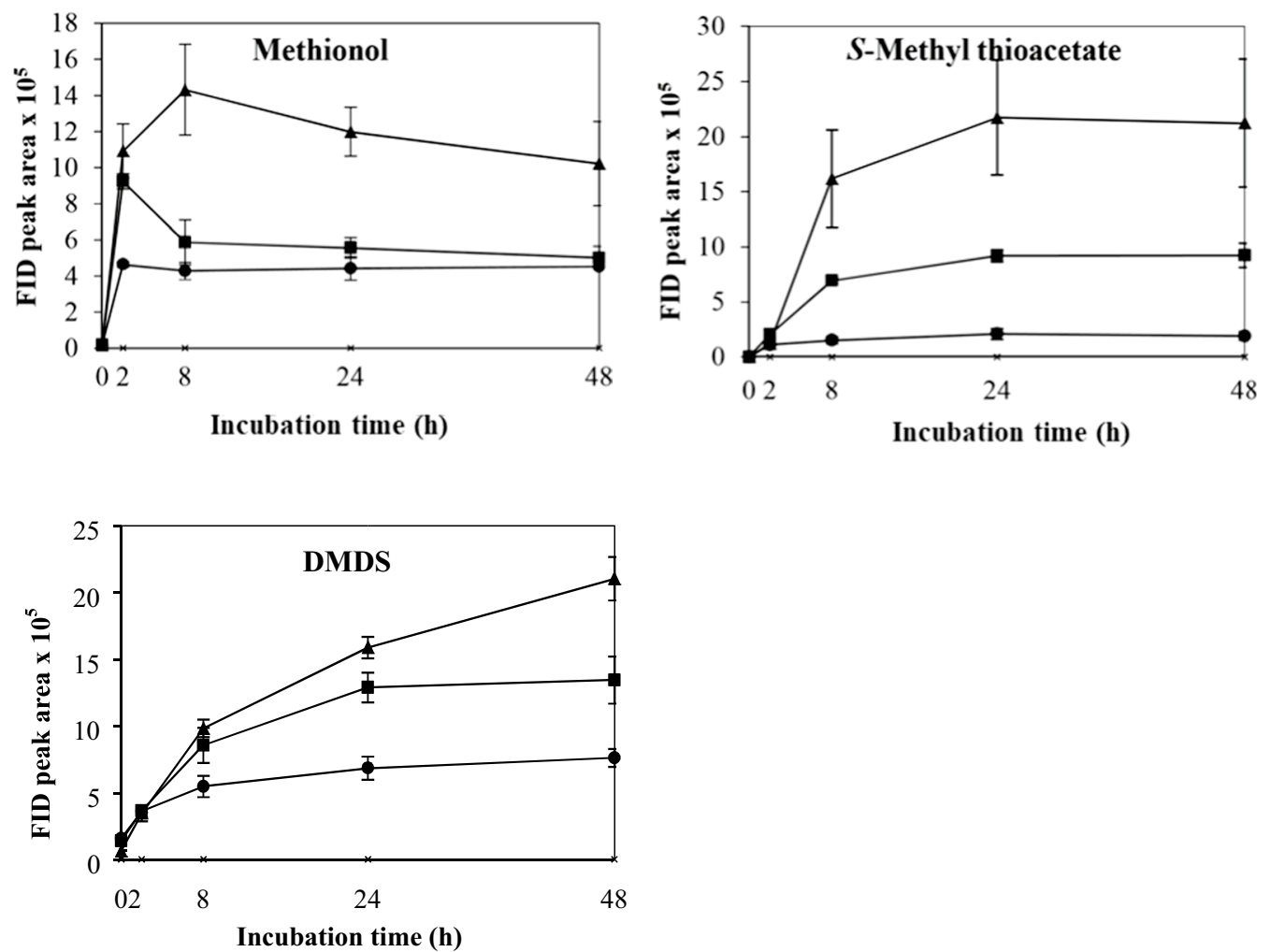

Fig. 1 Kinetics of volatile sulphur compound production during 48 h' incubation at $\mathrm{OD}_{600}$ levels of 2 (black circle), 4 (black square) and 6 (black up-pointing triangle) 

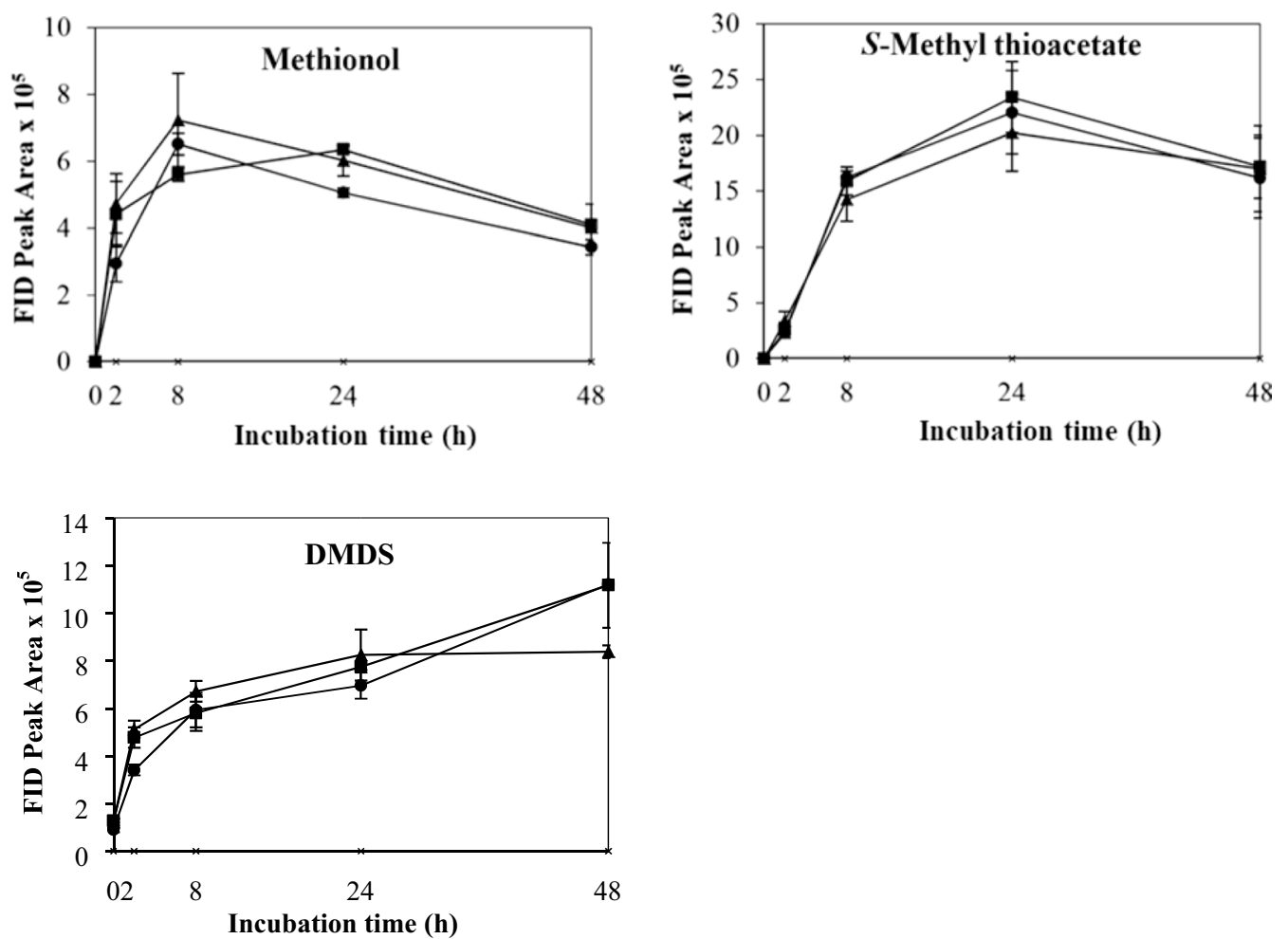

Fig. 2 Kinetics of volatile sulphur compound production during 48 h'incubation at L-methionine concentrations $0.1 \%$ (black circle), 0.5\% (black square) and 1.0\% (black up-pointing triangle)

than that at 80 and $120 \mathrm{rpm}$, where methionol increased to the maximum by $8 \mathrm{~h}$ and then declined slightly (Fig. 3). The production of MTA increased first and then declined gradually with agitations (Fig. 3). The highest production of MTA was found at $80 \mathrm{rpm}$ (Fig. 3) but there was no significant different in the final amount of MTA among the treatments (Additional file 1: Table S1). The production of DMDS followed similar trends except $120 \mathrm{rpm}$, which increased first by $24 \mathrm{~h}$ and then decreased slightly (Fig. 3). Significantly higher level of DMDS was found in samples treated at $80 \mathrm{rpm}$ (Additional file 1: Table S1). Although the production of MTA and DMDS were improved with aeration, tight enclosure of bottles and static incubation were adopted in subsequent treatments due to the clearly positive effect on methionol formation.

The effect of temperature on the production and kinetic changes of VSCs is shown in Fig. 4. The production of methionol followed a similar trend with the highest production at $30{ }^{\circ} \mathrm{C}$ (Fig. 4 and Additional file 1: Table S1). Trace amounts of MTA were produced when incubated at $38{ }^{\circ} \mathrm{C}$, while significantly higher levels were produced at 25 and $30{ }^{\circ} \mathrm{C}$ (Fig. 4 and Additional file 1: Table S1). In addition, relatively higher levels of MTA were produced at $30^{\circ} \mathrm{C}$ than that at $25^{\circ} \mathrm{C}$ but no significant difference. In contrast, the highest production of DMDS was found at $38^{\circ} \mathrm{C}$, which was significantly higher than that at 25 and $30{ }^{\circ} \mathrm{C}$ (Fig. 4 and Additional file 1: Table S1). Taking all VSCs into consideration, $30{ }^{\circ} \mathrm{C}$ was selected and used in subsequent treatments.

The effect of $\mathrm{pH}$ on the production and kinetic changes of VSCs is shown in Fig. 5. All VSCs followed similar trends where VSCs increased gradually (Fig. 5). The highest production of methionol, MTA and DMDS was found at $\mathrm{pH}$ 5.0, followed by $\mathrm{pH} 6.0$ and $\mathrm{pH} 4.0$ (Fig. 5 and Additional file 1: Table S1). These results indicated that the optimum pH for VSC formation was around 5.0, being consistent with the known optimum $\mathrm{pH}$ for yeast growth. Therefore, pH 5.0 was selected and used in subsequent treatments.

\section{Effects of nutrient supplementation on kinetic changes of VSCs by non-growing cells of $K$. lactis}

In the following treatments, the selected parameters with $\mathrm{OD}_{600} 6,1.0 \% \mathrm{~L}$-methionine, static incubation, $30{ }^{\circ} \mathrm{C}$ and $\mathrm{pH} 5$ were used to investigate the effects of specific nutrients on the production and kinetic changes of VSCs by non-growing cells of $K$. lactis.

The effect of nitrogen supplementation with DAP on the production and kinetic changes of VSCs is shown in Fig. 6. It seemed that nitrogen supplementation 

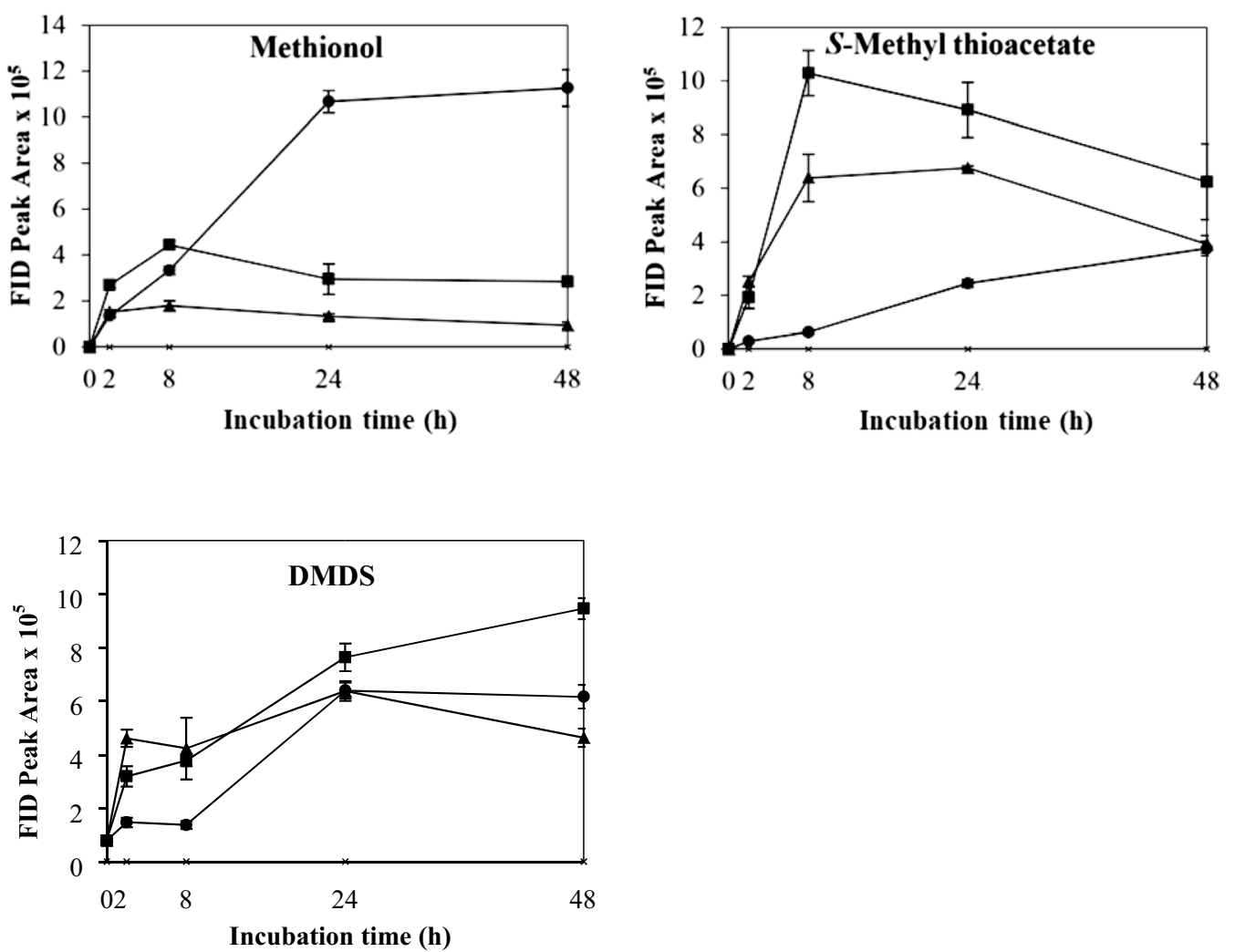

Fig. 3 Kinetics of volatile sulphur compound production during 48 h' incubation at agitation rates 0 rpm (black circle), 80 rpm (black square) and 120 rpm (black up-pointing triangle)

suppressed the production of VSCs with the control producing the highest level of methionol, MTA and DMDS, followed by 0.1 and $0.3 \%$ (Fig. 6). However, there is no significant difference in the final amount of DMDS among all treatments (Additional file 1: Table S1). It is interesting to note that trace levels of methional were detected in the treatments supplemented with DAP, though not statistically different (Additional file 1: Table S1).

The effect of yeast extract supplementation on the production and kinetic changes of VSCs is shown in Fig. 7. There is a significant impact of yeast extract on the production of methionol with $0.3 \%$ supplementation producing the highest level, followed by 0.1 and $0 \%$, respectively (Fig. 7 and Additional file 1: Table S1). The formation of methionol in $0.3 \%$ supplementation is around 2 times (in terms of FID peak area) higher than $0.1 \%$ supplementation and around 6 times higher than that in the control (Fig. 7 and Additional file 1: Table S1). Although yeast extract supplementation did not significantly boost the production of MTA and DMDS (Additional file 1: Table S1), there was an evident tendency to increase. Yeast extract supplementation induced the formation of methional with $0.3 \%$ addition producing the highest level, followed by $0.1 \%$; methional reached a maximum at
$24 \mathrm{~h}$, then declined. No methional was found in the control $(0 \%)$.

The effect of $\mathrm{Mn}^{2+}$ supplementation on the production and kinetic changes of VSCs is shown in Fig. 8. In the presence of $\mathrm{Mn}^{2+}$, more methionol was produced with more $\mathrm{Mn}^{2+}$ being added (Fig. 8 and Additional file 1: Table S1). However, $\mathrm{Mn}^{2+}$ reduced the formation of MTA with $10 \mathrm{mM}$ producing the lowest amount (Fig. 8 and Additional file 1: Table S1). $\mathrm{Mn}^{2+}$ supplementation significantly increased the production of DMDS (Fig. 8 and Additional file 1: Table S1). In contrast to nitrogen and yeast extract supplementation, methional was not detected (Additional file 1: Table S1).

\section{Effects of investigated parameters on cell survivability}

The yeast cell counts before and after incubation is summarized in Additional file 1: Table S2. The viable yeast cells were reduced after 48-h incubation in non-growth media except in treatments at $25{ }^{\circ} \mathrm{C}$ and yeast extract supplementation, where relatively higher cell counts were obtained but without significant difference relative to the respective initial cell counts (Additional file 1: Table S2). Significant decreases of viable yeast cells occurred in treatments at $\mathrm{pH} 4.0$ and $\mathrm{Mn}^{2+}$ supplementation 

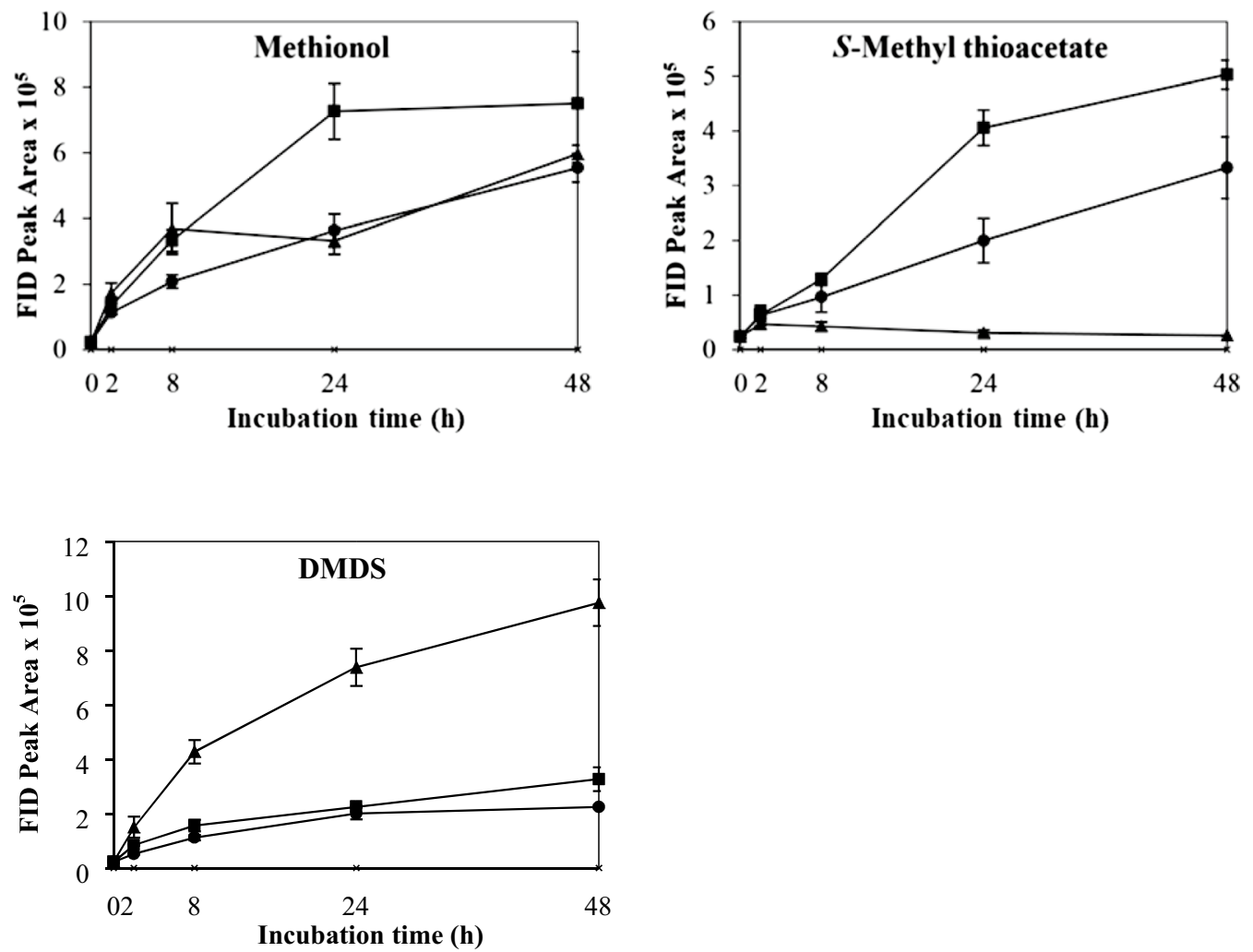

Fig. 4 Kinetics of volatile sulphur compound production during 48 h' incubation at temperatures $25^{\circ} \mathrm{C}$ (black circle), $30^{\circ} \mathrm{C}$ (black square) and $38^{\circ} \mathrm{C}$ (black up-pointing triangle)

(Additional file 1: Table S2). In addition, at $38^{\circ} \mathrm{C}$, no viable cell counts were obtained.

\section{Discussion}

\section{Effect of physicochemical parameters on VSC production by non-growing cells of $K$. lactis}

The influence of several physicochemical parameters on the production and kinetic changes of VSCs via the metabolism of L-methionine was investigated using nongrowing cells of $K$. lactis (Figs. 1, 2, 3, 4, 5). VSC production positively correlated with biomass, confirming the biological origin of VSCs (Fig. 1). Although no significant decline of L-methionine was observed (data not shown), the formation of VSCs remained stable after 48-h incubation, suggesting L-methionine was not rate-limiting. Our results are consistent with the findings of Etschmann et al. (2008) and Tan et al. (2012), who reported that no significant increase of methionol was observed in broth supplemented with L-methionine fermented by $S$. cerevisiae and Williopsis yeasts.

Aeration significantly affected the production of VSCs. The production of methionol was almost 12 times higher under static condition than with agitation (Fig. 3). This is expected as methionol formation is a reaction of reduction from methional catalyzed by alcohol dehydrogenase and is usually produced under oxygen-limited conditions (Tan et al. 2012). Our results differed from the finding of Hébert et al. (2011), where the K. lactis exponential growing cells did not produce any methionol under their condition; this could be due to the different cell states (non-growing cells of $K$. lactis used in this study). The decreased production of methionol under aeration could be related to repression of pyruvate decarboxylase and alcohol dehydrogenase activities by high oxygen levels (Landaud et al. 2008; Miyakoshi et al. 2016; Tan et al. 2012; Ugliano and Henschke 2009), since both enzymes are thought to be responsible for methionol formation through L-methionine catabolism (Miyakoshi et al. 2016; Tan et al. 2012). K. lactis is a respiro-fermentative yeast, it produces little or no alcohols under very high aeration, especially when sugar is limited (Becerra et al. 2004). In this study, however, no sugar was added and aerobic respiration was the key pathway of glucose (residual) conversion into pyruvate via glycolysis, and then to acetyl-CoA and $\mathrm{CO}_{2}$ via citric acid cycle (González-Siso et al. 2009).

In contrast, aeration significantly boosted MTA and DMDS formation initially, especially at $80 \mathrm{rpm}$, 

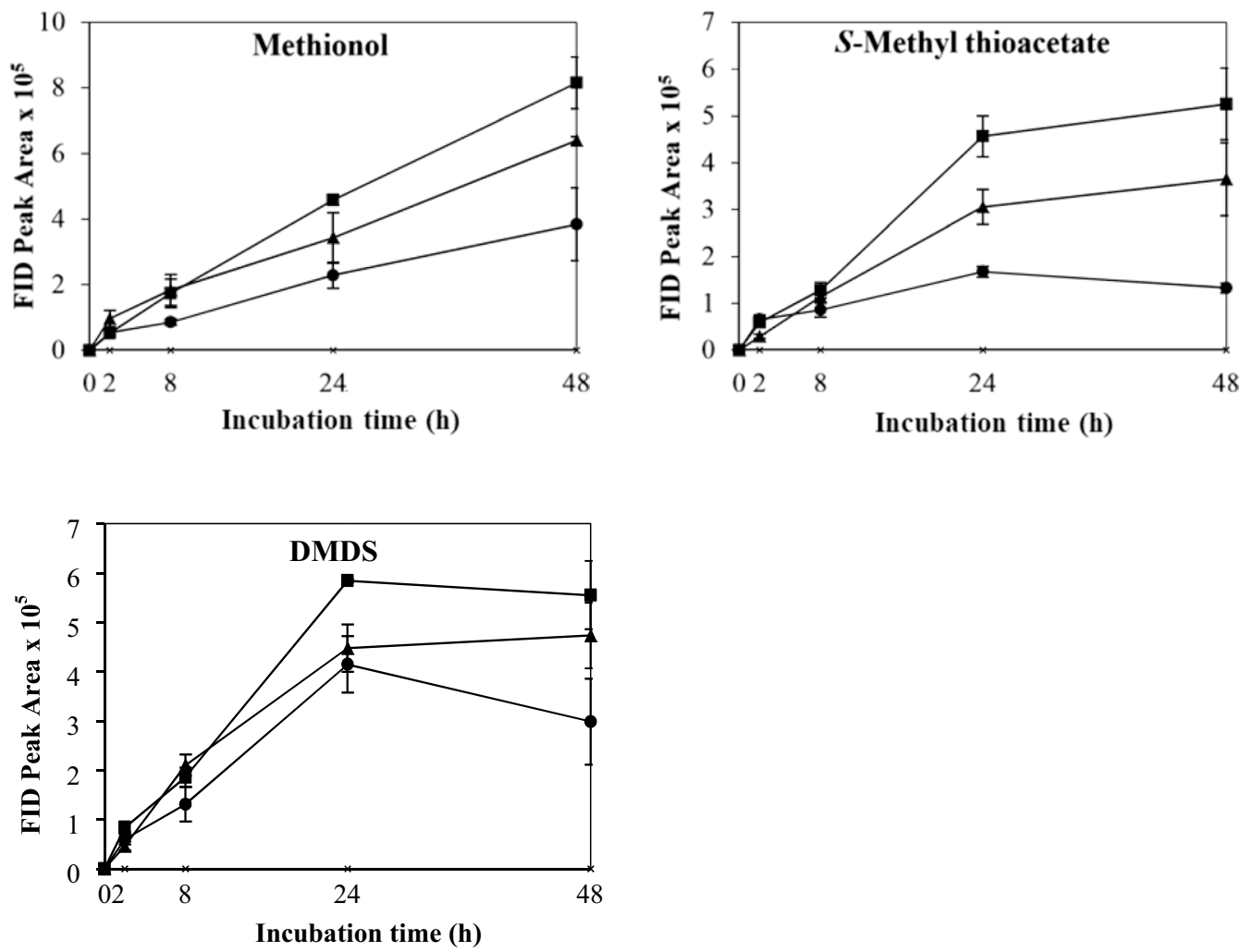

Fig. 5 Kinetics of volatile sulphur compound production during 48 h'incubation at pH 4 (black circle), 5 (black square) and 6 (black up-pointing triangle)

suggesting increased production of L-methioninederived methanethiol (a precursor common to both MTA and DMDS). This could be due to the respiro-fermentative nature of $K$. lactis that promoted the catabolism of L-methionine by aeration. Methanethiol then reacted with acetyl-CoA to form MTA or was oxidized to produce DMDS. On the other hand, since DMDS is an oxidized product of methanethiol and a lack of oxygen under static condition could inhibit the oxidation reactions, resulting in minor DMDS formation (Bonnarme et al. 2004). Nonetheless, for all analyzed VSCs, vigorous agitation could promote the volatilization of VSCs and their losses.

The highest levels of methionol and MTA were produced at $30{ }^{\circ} \mathrm{C}$ (Fig. 4). However, the production of methionol was not significantly different among all treatments except $38^{\circ} \mathrm{C}$ for MTA, which might indicate that temperature did not completely inhibit their formation, but partially inactivated the enzyme activity. The lowest level of MTA (known to be formed enzymatically, at least partially) was produced at $38{ }^{\circ} \mathrm{C}$, which might be due to the cell death of $K$. lactis (Additional file 1: Table S2). Helinck et al. (2000) investigated the effect of temperature on the production of MTA in G. candidum with the addition of methanethiol and acetyl-CoA and found that more MTA formation at higher temperatures (45 and $56^{\circ} \mathrm{C}$ ). By comparison, in our study, the highest level of DMDS was produced at $38^{\circ} \mathrm{C}$, which was inversely correlated with the lowest formation MTA at the same temperature. This negative correlation could be attributed to the exacerbation of thermally induced disulfide bond formation via oxidation of methanethiol as a result of diminished MTA formation (i.e. reduction of methanethiol consumption) and the availability of methanethiol (the precursor to both DMDS and MTA).

The $\mathrm{pH}$ significantly affected the production of VSCs (Fig. 5). The cell counts at $\mathrm{pH} 4.0$ declined sharply after incubation, then resulting in less production of VSCs. The highest production of VSCs was detected at $\mathrm{pH} 5.0$, which is considered as the optimum $\mathrm{pH}$ for the growth of $K$. lactis. Similar results were reported by Liu and Crow (2010) and Seow et al. (2010).

\section{Effects of nutrient supplementation on kinetic changes of VSCs by non-growing cells of $K$. lactis}

Nitrogen supplementation had a negative impact on the production of VSCs, as it reduced the formation of methionol, MTA and DMDS in comparison to 

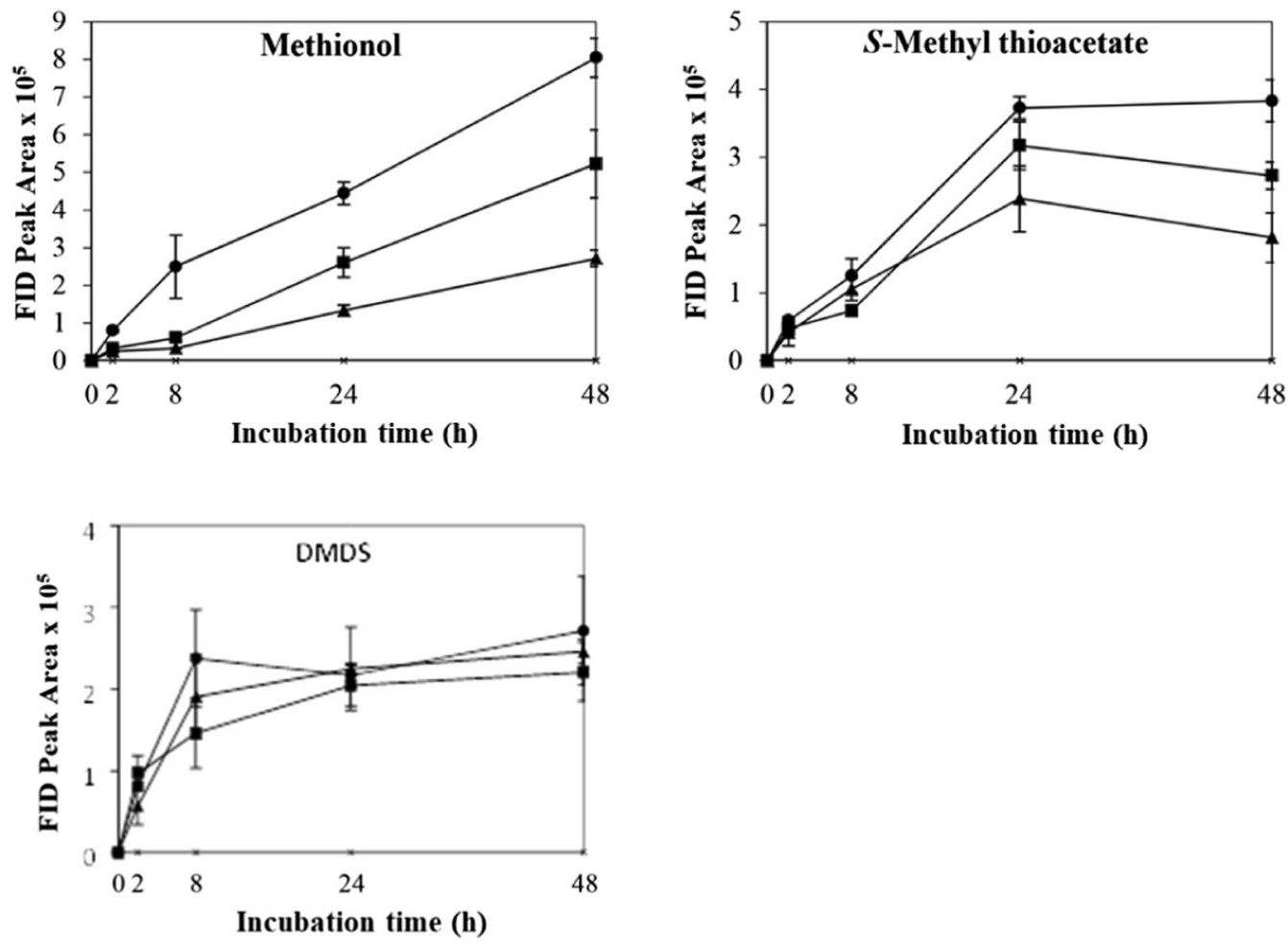

Fig. 6 Kinetics of volatile sulphur compound production during 48 h'incubation with nitrogen (diammonium phosphate) concentrations $0 \%$ (black circle), $0.1 \%$ (black square) and $0.3 \%$ (black up-pointing triangle)
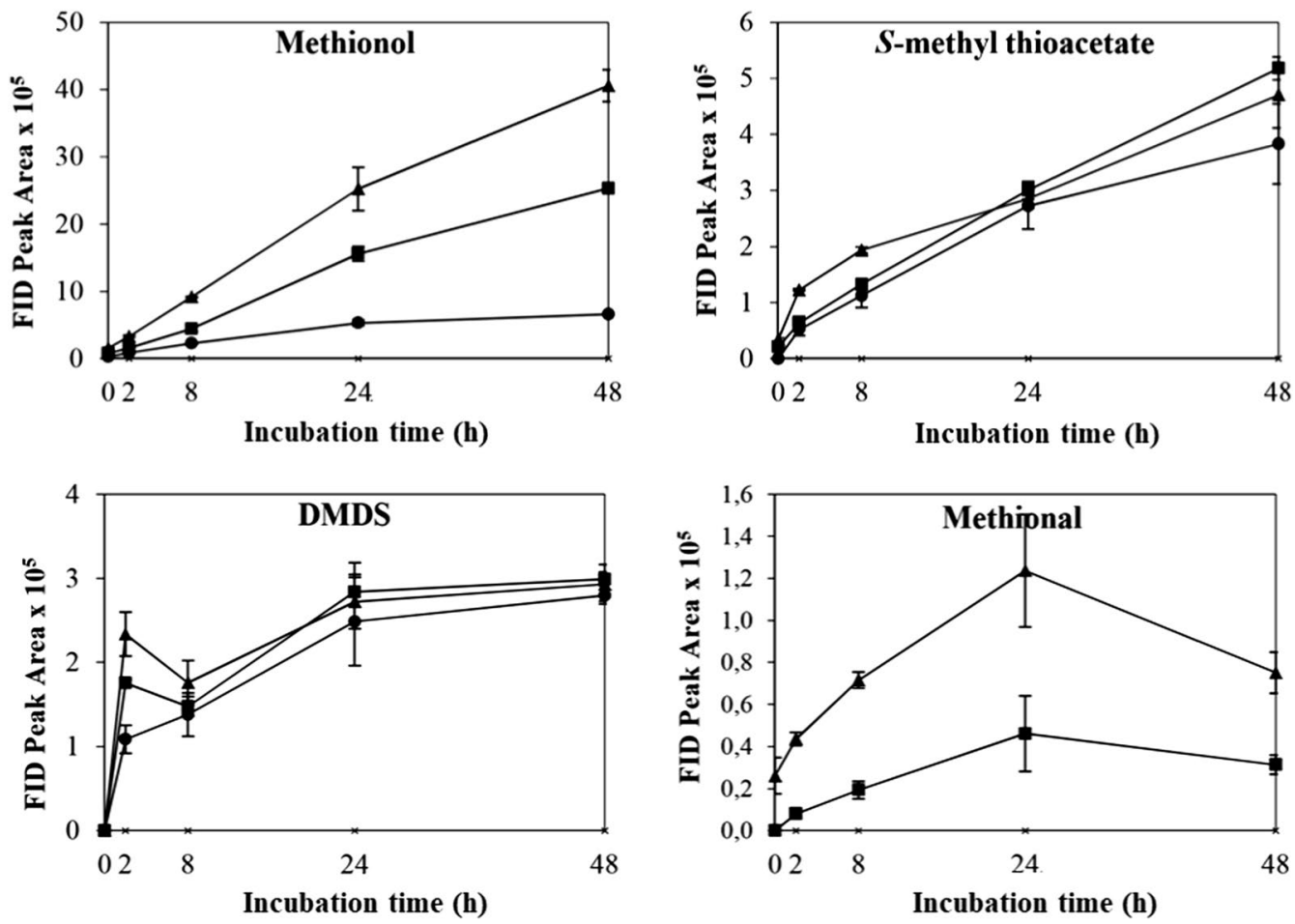

Fig. 7 Kinetics of volatile sulphur compound production during 48 h'incubation with yeast extract concentrations $0 \%$ (black circle), $0.1 \%$ (black square) and $0.3 \%$ (black up-pointing triangle) 

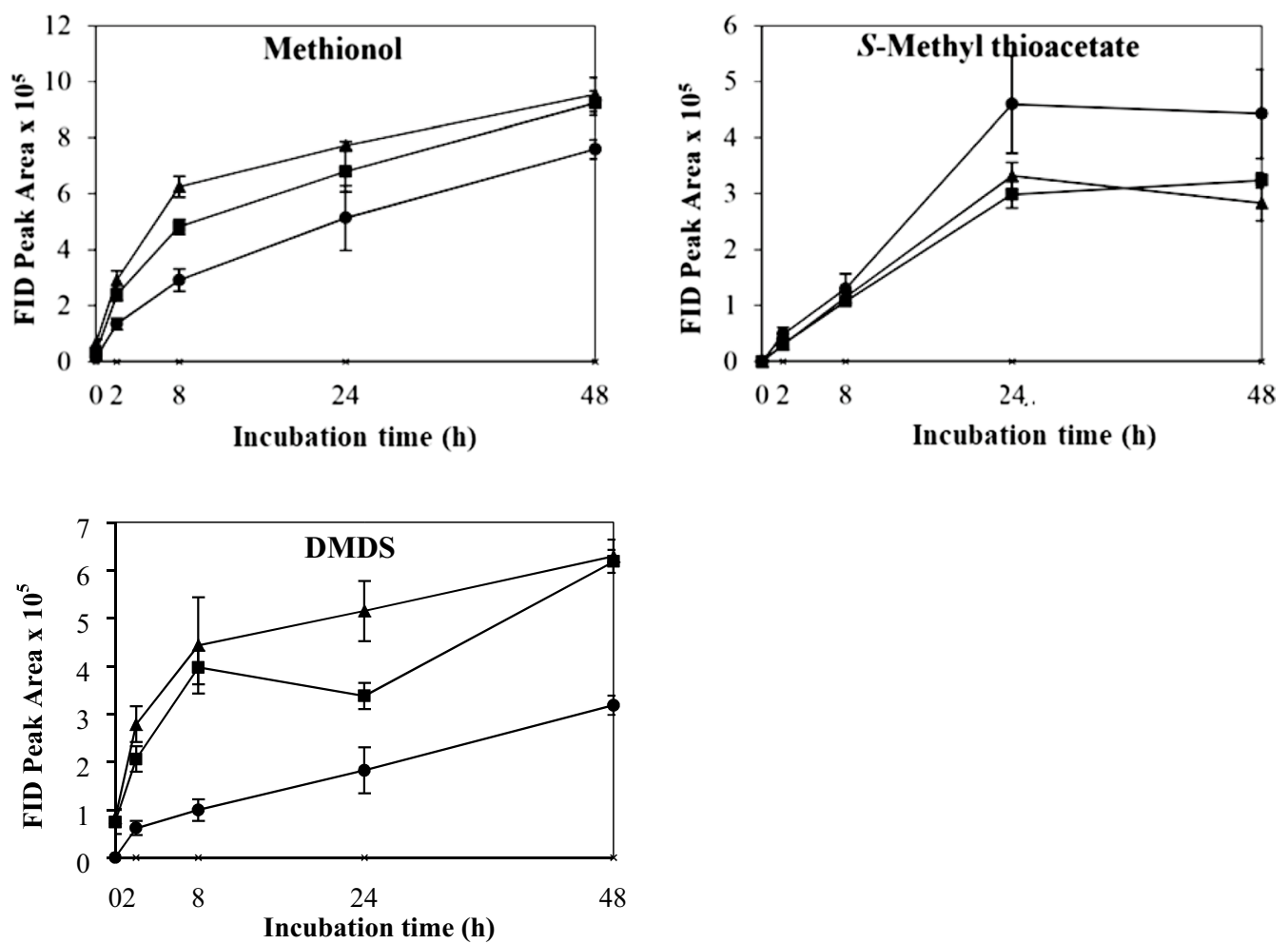

Fig. 8 Kinetics of volatile sulphur compound production during 48 h' incubation with $\mathrm{Mn}^{2+}$ concentrations $0 \mathrm{mM}$ (black circle), $1 \mathrm{mM}$ (black square) and $10 \mathrm{mM}$ (black up-pointing triangle)

non-supplemented samples (Fig. 6). (Hernández-Orte et al. 2005) investigated the addition of amino acids and ammonium salts to must for wine making and found that methionol produced from the ammonium addition was significantly reduced. Similar results were reported by Tan et al. (2012), who showed that a statistically significant decrease $(P<0.05)$ of VSC production with an increase of nitrogen supplementation $(0.05,0.10$ and $0.20 \%)$. The inhibition of formation of methionol, MTA and DMDS by nitrogen supplementation may indicate a direct or indirect biological transformation of L-methionine to these VSCs, rather than pure chemical degradation (Tan et al. 2012). Ammonium is an easily assimilable nitrogen sources over other forms by yeasts (Clement et al. 2013; Tan et al. 2012). An excess of ammonium than cellular reserves will negate the need for the catabolism of L-methionine and therefore decreasing the production of VSCs (Bisson 1991; ter Schure et al. 2000; Tan et al. 2012).

A significantly positive correlation exists between yeast extract concentration and VSC including methional production (Fig. 7). Yeast extract is composed of readily assimilable nitrogen sources such as amino acids and the water-soluble vitamin B complex. The marked increase of methionol could be related to the vitamin B complex, which is considered to be an indispensable cofactor in many enzymatic reactions. The activity of aminotransferase (ATase) is PLPdependent and PLP in turn arises from vitamin $B_{6}$. The ARO8 gene coding the ATase involved in $\mathrm{L}$-methionine degradation was identified in $K$. Lactis (Hébert et al. 2011). The crystal structure of $S$. cerevisiae Aro8 protein was determined and indicated the PLP cofactor binding (Bulfer et al. 2013). Therefore, due to the added amounts of vitamin $B_{6}$, ATase activity increased and expedited $\mathrm{L}$-methionine transamination and methionol production via the Ehrlich pathway. The boosted L-methionine catabolism and VSC production offset the nitrogen catabolite repression brought about by the amino acids from the yeast extract. The excretion of methional could be the result of accelerated rates of L-methionine transamination and $\alpha$-keto- $\gamma$-methylthiobutyric acid (KMBA, which could be excreted from the cells) production (Hébert et al. 2011), such that the rate of KMBA decarboxylation to methional was greater than that of methional reduction to methionol. However, methional formation may also be partially ascribed to Strecker degradation of L-methionine, which could be accelerated by riboflavin (vitamin $\mathrm{B}_{2}$ ) present in the yeast extract. 
Our results showed that $\mathrm{Mn}^{2+}$ could enhance the conversion of $\mathrm{L}$-methionine into methionol. $\mathrm{Mn}^{2+}$ is a co-factor of aminotransferase and/or decarboxylase, or $\mathrm{Mn}^{2+}$ could regulate redox conditions. Given that no related studies were reported and this hypothesis needs further investigation. However, the present study showed that transition metals seemed to be toxic to yeast cells, causing the relatively sharp decline of yeast population in the presence of $\mathrm{Mn}^{2+}$ (Additional file 1: Table S2). Interestingly, $\mathrm{Mn}^{2+}$ decreased MTA formation but increased DMDS production. It is known that DMDS is formed from the oxidation of methanethiol, a reaction that is catalyzed by transition metals and thus, the higher amount of DMDS with the addition of $\mathrm{Mn}^{2+}$ could be the result of methanethiol oxidation accentuated by $\mathrm{Mn}^{2+}$ (Chin and Lindsay 1994). By the same token, this explains the lower production of MTA (i.e. due to methanethiol being diverted to DMDS). In addition, the production of DMDS is not obligatorily dependent on yeast viability but availability of methanethiol, oxygen and catalyst(s).

In conclusion, the present study investigated for the first time the VSCs producing feasibility in a model system consisting of non-growing cells of $K$. lactis and L-methionine. Several pathways are involved in VSC formation through whole-cell-based catabolism of L-methionine which can be manipulated by adjusting physicochemical parameters and nutrient supplementation. The whole-cell system has proven to be a useful catalytic system, enhancing the biosynthesis of some VSCs. This study showed the feasibility of exploiting metabolically active non-growing cells in non-growth media to produce a range of sulphur-bearing, natural flavors from only one precursor, L-methionine. These produced VSCs might be widely used in food and beverage industries due to their high potency in flavor contributions. The findings may facilitate development of whole cell-based systems to produce these VSCs on a larger scale.

\section{Additional file}

Additional file 1: Table S1. Volatile sulphur compounds (Average FID peak area $\times 10^{5} \pm \mathrm{SD}$ ) produced during $48 \mathrm{~h}$ incubation. Table S2. K. lactis cell count $\left(\mathrm{CFU} / \mathrm{mL} \times 10^{7}\right)$ before $(0 \mathrm{~h})$ and after fermentation ( $48 \mathrm{~h}$ ).

\section{Abbreviations}

VSCs: volatile sulphur compounds; DMDS: dimethyl disulfide; DMTS: dimethyl trisulfide; MTA: S-methyl thioacetate; PDA: potato dextrose agar; $\mathrm{MnCl}_{2} \cdot 4 \mathrm{H}_{2} \mathrm{O}$ : manganese (II) chloride tetrahydrate; $\mathrm{NaH}_{2} \mathrm{PO}_{4} \cdot 2 \mathrm{H}_{2} \mathrm{O}$ : sodium phosphate monobasic dihydrate; $\mathrm{Na}_{2} \mathrm{HPO}_{4}$ : sodium phosphate dibasic anhydrous; DAP: diammonium phosphate; OD: optical density; HS-SPME-GC-MS-FID: head space solid-phase micro extraction coupled with gas chromatography-mass spectrometry and flame ionization detection; ANOVA: one-way analysis of variance; KMBA: a-keto- $\gamma$-methylthio-butyric acid production.
Authors' contributions

$Y L$ analysed and interpreted the data, wrote the manuscript. MN performed the experiment, collected the data. JS analysed and interpreted the data. SQL analysed, interpreted the data, and wrote and revised the manuscript. All authors read and approved the final manuscript.

\section{Author details}

${ }^{1}$ Food Science and Technology Program, Department of Chemistry, National University of Singapore, Science Drive 3, Singapore 117543, Singapore. ${ }^{2}$ National University of Singapore (Suzhou) Research Institute, 377 Lin Quan Street, Suzhou Industrial Park, Suzhou, Jiangsu 215123, China.

\section{Acknowledgements}

The authors would like to thank the Food Science and Technology Programme of the National University of Singapore for providing the research facilities.

\section{Competing interests}

The authors declare that they have no competing interests.

\section{Availability of data and materials}

The datasets supporting the conclusions of this article are included within the article.

Consent for publication

Not applicable.

Ethics approval and consent to participate

This article does not contain any studies with human participants or animals performed by any of the authors.

Funding

No funding was received for this study.

\section{Publisher's Note}

Springer Nature remains neutral with regard to jurisdictional claims in published maps and institutional affiliations.

Received: 31 May 2018 Accepted: 29 June 2018

Published online: 03 July 2018

References

Ahn DU, Lee EJ, Feng X, Zhang W, Lee JH, Jo C, Nam K (2016) Mechanisms of volatile production from sulfur-containing amino acids by irradiation. Radiat Phys Chem 119:80-84. https://doi.org/10.1016/j.radphysche m.2015.09.009

Arfi K, Spinnler H, Tache R, Bonnarme P (2002) Production of volatile compounds by cheese-ripening yeasts: requirement for a methanethiol donor for S-methyl thioacetate synthesis by Kluyveromyces lactis. Appl Microbiol Biotechnol 58:503-510. https://doi.org/10.1007/s0025 3-001-0925-0

Arfi K, Tâche R, Spinnler HE, Bonnarme P (2003) Dual influence of the carbon source and L-methionine on the synthesis of sulphur compounds in the cheese-ripening yeast Geotrichum candidum. Appl Microbiol Biotechnol 61:359-365. https://doi.org/10.1007/s00253-002-1217-z

Becerra M, Cerdán ME, Siso MIG (2004) Engineered autolytic yeast strains secreting Kluyveromyces lactis $\beta$-galactosidase for production of heterologous proteins in lactose media. J Biotechnol 109(1):131-137. https://doi. org/10.1016/j.jbiotec.2003.10.030

Bisson LF (1991) Influence of nitrogen on yeast and fermentation of grapes. In: Rantz JM (ed) Proceedings of the international symposium on nitrogen in grapes and wine. American Society for Enology and Viticulture, Davis, pp $78-89$

Bonnarme P, Amarita F, Chambellon E, Semon E, Spinnler HE, Yvon M (2004) Methylthioacetaldehyde, a possible intermediate metabolite for the production of volatile sulphur compounds from L-methionine by Lactococcus lactis. FEMS Microbiol Lett 236:85-90. https://doi. org/10.1111/j.1574-6968.2004.tb09631.x 
Bulfer SL, Brunzelle JS, Trievel RC (2013) Crystal structure of Saccharomyces cerevisiae Aro8, a putative a-aminoadipate aminotransferase. Protein Sci 22:1417-1424. https://doi.org/10.1002/pro.2315

Cernat-Bondar D, Beckerich JM, Bonnarme P (2005) Involvement of a branched-chain aminotransferase in production of volatile sulfur compounds in Yarrowia lipolytica. Appl Environ Microbiol 71:4585-4591. https ://doi.org/10.1128/AEM.71.8.4585-4591.2005

Chin HW, Lindsay RC (1994) Ascorbate and transition-metal mediation of methanethiol oxidation to dimethyl disulfide and dimethyl trisulfide. Food Chem 49:387-392. https://doi.org/10.1016/0308-8146(94)90009-4

Cholet O, Hénaut A, Casaregola S, Bonnarme P (2007) Gene expression and biochemical analysis of cheese-ripening yeasts: focus on catabolism of L-methionine, lactate, and lactose. Appl Environ Microbiol 73:2561-2570. https://doi.org/10.1128/AEM.02720-06

Clement T, Perez M, Mouret JR, Sanchez I, Sablayrolles JM, Camarasa C (2013) Metabolic responses of Saccharomyces cerevisiae to valine and ammonium pulses during four-stage continuous wine fermentations. Appl Environ Microbiol 79(8):2749-2758. https://doi.org/10.1128/AEM.02853-12

Etschmann MMW, Kötter P, Hauf J, Bluemke W, Entian KD, Schrader J (2008) Production of the aroma chemicals 3-(methylthio)-1-propanol and 3-(methylthio)propylacetate with yeasts. Appl Microbiol Biotechnol 80:579-587. https://doi.org/10.1007/s00253-008-1573-4

Fuchsmann P, Stern MT, Brügger YA, Breme K (2015) Olfactometry profiles and quantitation of volatile sulfur compounds of Swiss tilsit cheeses. J Agric Food Chem 63(34):7511-7521. https://doi.org/10.1021/acs.jafc.5b02536

Gonda I, Lev S, Bar E, Sikron N, Portnoy V, Davidovich-Rikanati R, Burger J, Schaffer AA, Tadmo YA, Giovannonni JJ, Huang M, Fei Z, Katzir N, Fait A, Lewinsohn E (2013) Catabolism of L-methionine in the formation of sulfur and other volatiles in melon (Cucumis melo L.) fruit. Plant J 74:458-472. https://doi.org/10.1111/tpj.12149

González-Siso MI, García-Leiro A, Tarrío N, Cerdán ME (2009) Sugar metabolism, redox balance and oxidative stress response in the respiratory yeast Kluyveromyces lactis. Microb Cell Fact 8(1):46-62. https://doi. org/10.1186/1475-2859-8-46

Hanniffy SB, Peláez C, Martínez-Bartolomé MA, Requena T, Martínez-Cuesta MC (2009) Key enzymes involved in methionine catabolism by cheese lactic acid bacteria. Int J Food Microbiol 135:223-230. https://doi.org/10.1016/j. ijfoodmicro.2009.08.009

Hazelwood LA, Daran JM, van Maris AJA, Pronk JT, Dickinson JR (2008) The Ehrlich pathway for fusel alcohol production: a century of research on Saccharomyces cerevisiae metabolism. Appl Environ Microbiol 74:22592266. https://doi.org/10.1128/AEM.02625-07

Hébert A, Forquin-Gomez MP, Roux A, Aubert J, Junot C, Loux V, Heilier JF, Bonnarme P, Beckerich JM, Landaud S (2011) Exploration of sulfur metabolism in the yeast Kluyveromyces lactis. Appl Microbiol Biotechnol 91:1409-1423. https://doi.org/10.1007/s00253-011-3481-2

Helinck S, Spinnler HE, Parayre S, Dame-Cahagne M, Bonnarme P (2000) Enzymatic versus spontaneous S-methyl thioester synthesis in Geotrichum candidum. FEMS Microbiol Lett 193:237-241. https://doi. org/10.1111/j.1574-6968.2000.tb09430.x

Hernández-Orte P, Ibarz MJ, Cacho J, Ferreira V (2005) Effect of the addition of ammonium and amino acids to musts of Airen variety on aromatic composition and sensory properties of the obtained wine. Food Chem 89:163-174. https://doi.org/10.1016/j.foodchem.2004.02.021

Julsing MK, Kuhn D, Schmid A, Bühler B (2012) Resting cells of recombinant $E$. coli show high epoxidation yields on energy source and high sensitivity to product inhibition. Biotechnol Bioeng 109:1109-1119. https://doi. org/10.1002/bit.24404

Kagkli DM, Bonnarme P, Neuvéglise C, Cogan TM, Casaregola S (2006a) L-Methionine degradation pathway in Kluyveromyces lactis: identification and functional analysis of the genes encoding L-methionine aminotransferase. Appl Environ Microbiol 72:3330-3335. https://doi.org/10.1128/ AEM.72.5.3330-3335.2006
Kagkli DM, Tâche R, Cogan T, Hill C, Casaregola S, Bonnarme P (2006b) Kluyveromyces lactis and Saccharomyces cerevisiae, two potent deacidifying and volatile-sulphur-aroma-producing microorganisms of the cheese ecosystem. Appl Microbiol Biotechnol 73:434-442. https://doi. org/10.1007/s00253-006-0461-z

Landaud S, Helinck S, Bonnarme P (2008) Formation of volatile sulfur compounds and metabolism of methionine and other sulfur compounds in fermented food. Appl Microbiol Biotechnol 77:1191-1205. https://doi. org/10.1007/s00253-007-1288-y

Liu SQ, Crow VL (2010) Production of dairy-based, natural sulphur flavor concentrate by yeast fermentation. Food Biotechnol 24:62-77. https://doi. org/10.1080/08905430903562724

Martínez-Cuesta MDC, Peláez C, Requena T (2013) Methionine metabolism: major pathways and enzymes involved and strategies for control and diversification of volatile sulfur compounds in cheese. Crit Rev Food Sci Nutr 53:366-385

McGorrin RJ (2011) The significance of volatile sulfur compounds in food flavors: an overview. In: Qian MC, Fan X, Mahattanatawee K (eds) volatile sulfur compounds in food. American Chemical Society, Washington, D.C., pp 3-31. https://doi.org/10.1021/bk-2011-1068.ch001

Merico A, Galafassi S, Piškur J, Compagno C (2009) The oxygen level determines the fermentation pattern in Kluyveromyces lactis. FEMS Yeast Res 9:749-756. https://doi.org/10.1080/10408398.2010.536918

Mestres M, Busto O, Guasch J (2000) Analysis of organic sulfur compounds in wine aroma. J Chromatogr A 881:569-581. https://doi.org/10.1016/S0021 $-9673(00) 00220-X$

Miyakoshi S, Negishi Y, Sekiya Y, Nakajima S (2016) Improved conversion of cinnamaldehyde derivatives to diol compounds via a pyruvate decarboxylase-dependent mechanism in budding yeast. J Biosci Bioeng 121(3):265-267. https://doi.org/10.1016/j.jbiosc.2015.06.013

Ochiai N, Sasamoto K, MacNamara K (2012) Characterization of sulfur compounds in whisky by full evaporation dynamic headspace and selectable one-dimensional/two-dimensional retention time locked gas chromatography-mass spectrometry with simultaneous element-specific detection. J Chromatogr A 1270:296-304. https://doi.org/10.1016/j. chroma.2012.11.002

Rodicio R, Heinisch JJ (2013) Yeast on the milky way: genetics, physiology and biotechnology of Kluyveromyces lactis. Yeast 30:165-177. https://doi. org/10.1002/yea.2954

Schulbach KF, Rouseff RL, Sims CA (2004) Relating descriptive sensory analysis to gas chromatography/olfactometry ratings of fresh strawberries using partial least squares regression. J Food Sci 69:273-277. https://doi. org/10.1111/j.1365-2621.2004.tb13628.x

Seow YX, Ong PKC, Liu SQ (2010) Production of flavor-active methionol from methionine metabolism by yeasts in coconut cream. Int J Food Microbiol 143:235-240. https://doi.org/10.1016/j.ijfoodmicro.2010.08.003

Spinnler HE, Berger C, Lapadatescu C, Bonnarme P (2001) Production of sulfur compounds by several yeasts of technological interest for cheese ripening. Int Dairy J 11:245-252. https://doi.org/10.1016/S0958-6946(01)00054 $-1$

Tan AJ, Lee PR, Seow YX, Ong PC, Liu SQ (2012) Volatile sulphur compounds and pathways of L-methionine catabolism in Williopsis yeasts. Appl Microbiol Biotechnol 95:1011-1020. https://doi.org/10.1007/s0025 3-012-3963-x

ter Schure EG, van Riel NA, Verrips CT (2000) The role of ammonia metabolism in nitrogen catabolite repression in Saccharomyces cerevisiae. FEMS Microbiol Rev 24(1):67-83. https://doi.org/10.1111/j.1574-6976.2000.tb00533.x

Ugliano M, Henschke PA (2009) Yeasts and wine flavor. In: Moreno-Arribas MV, Polo MC (eds) Wine chemistry and biochemistry. Springer, New York, USA, pp 314-374

Xiao DR, Liu RS, He L, Li HM, Tang YL, Liang XH, Tang YJ (2015) Aroma improvement by repeated freeze-thaw treatment during Tuber melanosporum fermentation. Sci Rep 5:17120-17130. https://doi.org/10.1038/srep17120 